\title{
Comparative modeling of hull form resistance for three ocean going vessels using methodical series
}

\author{
Nitonye Samson *, Adumene Sidum \\ Department of Marine Engineering, Rivers State University of Science and Technology Port Harcourt, Rivers State, Nigeria \\ *Corresponding authorE-mail: sidum.adumene@ust.edu.ng
}

Copyright $\odot 2015$ Nitonye Samson, Adumene Sidum. This is an open access article distributed under the Creative Commons Attribution License, which permits unrestricted use, distribution, and reproduction in any medium, provided the original work is properly cited.

\begin{abstract}
This paper presents a comparative estimation of the hull form resistance for Cargo ship, Ocean-going Tug and Container ship. The research study evaluates the influences of various ship hull parameters in relations to the vessel speeds and level of turbulence (Reynolds number). The modeling was done using MATLAB software and the model test technique based on the ITTC, ATTC, Granville and Hughes friction line application. The result shows that the hull form resistances follow the same trend in the ITTC, ATTC and Granville models, while the Hughes model gave a different trend with other techniques. It further revealed that as the speed increases by 10knots, the frictional resistance coefficients decrease by $11.86 \%$ for the ITTC \& Granville models, and $12.03 \%$ for the Hughes model. For Ocean-going Tug and Container Ship, the frictional resistance coefficient decrease by $12.31 \%$ for the ITTC \& Granville models, and $12.14 \%$ for the Hughes model. The Reynolds number increase by $62.52 \%$ for every $10 \mathrm{knots}$ increase in the speed of the Cargo ship and $62.23 \%$ for every $10 \mathrm{knots}$ increase in the speed of the Ocean going tug and Containership. At various experimental speeds, the results showed that for every 1 knots increase in the speed of the Containership, the effective power developed increases by $9.45 \%$. This provides a technical and analytical guide on hull form resistance trend for engineers and ship operators.
\end{abstract}

Keywords: Resistance; Ships; Hull; ITTC; ATTC; Granville; Hughes.

\section{Introduction}

Ships differ from any other larger engineering structure because of its complexity in design and operations. It therefore, demands that ship design must be done professionally and effectively, including the principles of it operation to achieve a minimum resistance by external forces [1]. The ship motion in water is dependent on the propulsion and shape or form of the hull; the size and type of propulsion plant needed to transform the power into an effective thrust.

Hull based resistance is an important parameter that influences ship performance at sea. The knowledge of a predictive estimation of the various resistive factors on the hull form is paramount to optimize ship performance and operation [2]. The effect of ship resistance on ship propulsion performance is of importance to ship designer. The resistance of a ship at a given speed is the force required to tow the ship at that speed in smooth water, assuming no interference from the towing ship [3]. If the hull has no appendages, this is called the bare-hull, or towing resistance, and although very near to, it is not exactly the same as the propulsion resistance due to hull-propeller interactions [1].

This total resistance is made up of a number of different components, which are caused by a variety of factors and, which interact with each other in a complex fashion. Analyzing the hull form resistance in calm water, we considered four main resistance components [4].

Frictional resistance on the hull is due to the motion of the hull through viscous fluid. Eddy resistance on the hull is due to energy carried away by eddies shed from the hull [5]. This is severe at the astern where the water may be unable to follow the curvature and will break away from the hull, giving rise to eddies and separation resistance. Wave making resistance is due to energy that must be supplied continuously by the ship to the wave system created on the free surface 
[6]. Air resistance experienced by the above water part of the main hull and the super structures due to the motion of the ship through the air.

The waves making resistance and eddy resistance are commonly considered together under the residuary resistance. Although the wave making resistance dominate the total ship resistance and do create practical barrier in operation. The wave amplitude $A(\varnothing)$ is always predicted from theory. Havelock [7] presented an analytical approach for predicting the wave resistance of ships. Its essential assumptions are that the hull is thin, that is the beam is small compared to all other characteristic lengths of the problem. The resulting solution of the approach can be expressed in terms of a distribution of sources and sinks on the center plane of the hull, with local source strength proportional to the longitudinal slope of the hull [8]. This approach is analogous to the thickness problem of thin wing theory in aerodynamics [9]-[10].

Effects of shallow water on ship resistance and power are of importance for inland vessels and larger vessels in shallow waterway [11]. Limited water depth can affect viscous and wave resistance, sinkage and trim, propulsive efficiency and far-field wave systems. This also accounts for a slight and sudden resistance increase for ship in shallow waters [12].

In practical situation, the fluid velocity distribution past the hull will be greater than the speed of advance along the mid-portion, and the region of bow and stern will be less. The pressure distribution also demonstrated a pattern of impact: it is higher at the bow and stern, and lower in the mid-portion [13]. The resulting pressure distribution on the hull results in the creation of a wave system which spreads out astern of the vessel and has to be continuously recreated [14].

\section{Material and methods}

\subsection{Research Models}

This research work employed various methodical series in analyzing the total resistance on three model vessels, such as Cargo ship, Ocean-going tug, and Container ships. The series adopted for the modeling include:

\subsubsection{Froude William Friction Model}

In the nineteen century, Froude undertook a basic investigation as regards frictional resistance of smooth planks in his tank at Torquacy. He gave an empirical formula for the frictional resistance in the form $\mathrm{R}=\mathrm{f} . \mathrm{S}^{\mathrm{n}}$ where $\mathrm{n}=1.825$, $\mathrm{R}$ is the resistance $(\mathrm{Ib}), \mathrm{f}$ vary with the ship speed, $\mathrm{S}$ is the total surface (wetted area) in $\mathrm{ft}^{2}$. He tried the experiments with different surfaces and discovered that for a smooth varnished surface the value of the exponent " $n$ " decreased from 2.0 for the short plank to 1.83 for 50 foot plank [3]. Again, the value of "f" decreased with increasing length and for a given length it increased with surface toughness. It is also influence by the speed variation

Froude in his work found that the actual ship resistance was higher than the predicted from the model, the percentage increase becoming less with increasing speed [9]. There exists some difference in $\mathrm{R} / \mathrm{V}^{3}$, however it was almost the same at all speeds in the three vessels studied. It also showed that increase in the speed might occur, if this additional resistance were of the division type at a lower rated power [15].

\subsubsection{ITTC 1957 Friction Lines}

The International Towing Tank Conference (ITTC) agreed to adopt the Froude method for model extrapolation on the determination of the length and wetted surfaces [9].

The Froude's skin - friction deduction of $R_{\mathrm{f}}=\left[0.00871+\left(\frac{0.0053}{8.8+\mathrm{L}}\right)\right] \mathrm{SV}^{1.825}$

Where $R_{\mathrm{f}}$ is the resistance $(\mathrm{kN})$, $\mathrm{L}$ the length $(\mathrm{m}), \mathrm{S}$ the wetted surface area $\left(\mathrm{m}^{2}\right)$ and $\mathrm{V}$ the speed $(\mathrm{m} / \mathrm{s})$.

The Froude's deduction shows that the model results should be corrected to a standard temperature of $15^{\circ} \mathrm{C}$ by a corrected factor of $+0.43 \%$ of the frictional resistance per ${ }^{0} \mathrm{C}$.

For fresh water consideration,

The Froude's skin - friction deduction of $\mathrm{R}_{\mathrm{f}}=\left[0.0849+\left(\frac{0.0516}{8.8+\mathrm{L}}\right)\right] \mathrm{SV}^{1.825}$

And

$\mathrm{C}_{\mathrm{f}}=\frac{0.075}{\left(\log _{10} \mathrm{R}_{\mathrm{N}}-2\right)^{2}}$

where Reynolds number $\mathrm{R}_{\mathrm{n}}=\frac{\mathrm{V} \mathrm{L}}{\mathrm{v}}$ 


\subsubsection{ATTC (schoenher) Friction Lines}

The American Towing Tank Conference (ATTC) 1974, utilized line developed by K.E Schoenher for expressing the specific friction drag of turbulent flow on flat, smooth surfaces as a function of Reynolds number. It analyzed an additive allowance in form of a specific friction resistance with a +0.004 consideration of effect of unavoidable roughness on a clean, new ship [3].

It gave the expression $\frac{0.242}{\sqrt{C_{\mathrm{f}}}}=\log _{10}\left(\mathrm{R}_{\mathrm{n}}+\mathrm{C}_{\mathrm{f}}\right)$

\subsubsection{Granville's Friction Lines}

The Granville's technique is sometime used and it usually results in predictions that fall between Froude (high) and Hughes (low). Granville's friction line was derived in 1977. It estimate the total resistance coefficient as

$$
\mathrm{C}_{\mathrm{T}}=\mathrm{C}_{\mathrm{V}}+\mathrm{C}_{\mathrm{w}}
$$

where the wave making reistance coefficient is $C_{w}=C_{w}\left(f_{n}\right)$ and the viscous resistance coefficient is

$C_{v}=(1+k) C_{v o}\left(R_{e}\right)\left(f_{n}\right)$

The Granville's friction model $C_{f o}=\frac{0.0776}{\left(\log _{10} R_{e}-1.88\right)^{2}}+\frac{60}{R_{e}}$

\subsubsection{Hughes Friction Lines}

The Hughes in 1963 proposed a variation in the Granville's friction as $C_{f o}=\frac{0.066}{\left(\log _{10} R_{e}-2.03\right)^{2}}$ which represents the frictional resistance coefficient in two dimensional flows. He assumed that the total model resistance coefficient $\left(\mathrm{C}_{\mathrm{fm}}\right)$ could be divided into two parts $\mathrm{C}_{\mathrm{vm}}$ and $\mathrm{C}_{\mathrm{wm}}$, representing the viscous and wave making resistance. This is a step towards avoiding the negative allowances sometimes found when using the Froude friction model.

\subsection{Hull Form Effect of Resistance Reduction}

i) The Bulbous Bows

The bulbous bow is one of the ways in which the wave -making resistance could be reduced on vessels as indicated in model test experiment with reference to those ships that sail at high speed-length ratios. By the incorporation of large bulbous bow, many vessels can reduce resistance problems especially when the bulbous are large enough to have a section area equal to $8 \%$ of their amid ship section area [10].

ii) Length

The wave-making resistance is reduced by increasing the length of a vessel, which in turn reduced the speed-length. Increases this has the tendency to increase the wetted surface area which could increase the frictional resistance

iii) Beam - Draught Ratio

This is usually expressed as $\mathrm{B} / \mathrm{H}$, which is equal to about 3 . For a continuous increase of the beam, the draught decreases sequentially, but when at a low rate. Finally, if the resistance decreases lightly, the ratio become smaller as observed in model test results.

iv) Displacement - Length Ratio

For the fast moving vessels, the lower the displacement length ratio, the easier the vessel will drive in proportion to her displacement.

\subsection{Numerical / Model Experimental Technique}

The most important analysis used here to examine the ship resistance components, for instance, the residuary, frictional resistance, air resistance and the like could be obtained by the similarity theory of Froude. Thus an analytical modeling is considered together with the experiment to distinguish the wave resistance influence on the ship and the friction factor [14].

The Hull form resistance tests in calm water and regular wave's pattern were carried out in the towing tank $60 \mathrm{~m} \times 2 \mathrm{~m} x$ $1.5 \mathrm{~m}$. The residuary resistance of geometrically similar ship in the ratio of the cube of their speeds was analysed, and also in the ratio of the square root of their linear dimensions. To achieve this, the following steps were taken:

i) The model is made to a linear scale ratio $(\boldsymbol{\lambda})$ to run over a range of stipulated corresponding speeds with resistance

ii) The model total resistance Rtm is measured 
iii) The opposing frictional resistance $\mathrm{Rfm}$ of the model is measured

iv) The residuary resistance Rrm of the model is evaluated

v) The total and bare- hull resistance of the ship are model by $R_{T S}=R_{f s}+R_{r s}$

The linear ratio due to resistance of model and ship is expressed as

$R_{r s}=\lambda^{3} R_{r m}$

Guldharmer and Harvald in ship resistance effect of form and principal dimension (Akademisk Forlag, Capenhagen 1974) [6], defines the total resistance $R_{T}$ as

$$
R_{T}=C_{T} \cdot \frac{1}{2} \cdot \rho \cdot S \cdot V^{2} \text { and } C_{T}=R_{f}+R_{r}
$$

The relationship of the resistance is expressed as

$R_{T S}=R_{B H_{T}}+R_{\text {Air }}+R_{A p p}+\ldots . R_{n}$

$R_{B H_{T}}=R_{f}+R_{n}$

Frictional Resistance for the Ship

$$
R_{f}=R_{f s}=\frac{1}{2} \cdot C_{f s} \cdot \rho_{s w} \cdot S_{s} \cdot V_{s}^{2}
$$

Frictional Resistance for the model

$$
R_{f}=R_{f m}=\frac{1}{2} \cdot C_{m} \cdot \rho_{s w} \cdot S_{m} \cdot V_{m}{ }^{2}
$$

For Air Resistance of the model

$$
R_{a m}=\frac{1}{2} \cdot C_{\text {air }} \cdot \rho_{\text {air }} \cdot A_{T} \cdot V_{\text {air }}{ }^{2}
$$

Several theoretical methods and assumptions have been used to model the total resistance of ocean going vessels in calm water and regular wave pattern.

Aribas [5] and Strom-Jejsen [8] presented the prediction of added resistance effect on vessel performance using Gerritsma and Beukelmen method. They were able to model the resistance using sectional offsets or sectional geometric coefficients for the vessel.

\section{Results and Discussion}

\begin{tabular}{|c|c|}
\hline Parameters & Value \\
\hline Length Overall $\mathrm{L}_{\mathrm{OA}}$ & $121.92 \mathrm{~m}$ \\
\hline Length Between Perpendicular $\mathrm{L}_{\mathrm{pp}}$ & $96.0198 \mathrm{~m}$ \\
\hline Breadth $\mathrm{B}_{\mathrm{x}}$ & $18.519 \mathrm{~m}$ \\
\hline Height $\mathrm{H}$ & $8.48868 \mathrm{~m}$ \\
\hline Volume Displacement & $1399.388 \mathrm{~m}^{3}$ \\
\hline Mass Displacement & 13317tons \\
\hline Wetted Surface Area S & $3428.01 \mathrm{~m}^{2}$ \\
\hline Block Coefficient $C_{B}$ & 0.688 \\
\hline Prismatic Coefficient $C_{P}$ & 0.695 \\
\hline $\mathrm{B}_{\mathrm{x}} / \mathrm{H}$ & 2.18 \\
\hline $\mathrm{V}_{\mathrm{s}}$ & $4.112 \mathrm{~m} / \mathrm{s}$ \\
\hline $\mathrm{T}(\mathrm{sw})$ & $15^{0} \mathrm{C}$ \\
\hline
\end{tabular}

The equations were modeled using MATLAB Software for the Cargo ship, Ocean-going Tug and Container ship. The ships particular and the simulation results are highlighted in Tables 1- 8

Table 1: Cargo Ship Main Particular 
Table 2: Numerical Result for Cargo Ship

\begin{tabular}{llccc}
\multicolumn{5}{c}{ Table 2: Numerical Result for Cargo Ship } \\
\hline Methods & Resistance & & $\mathrm{C}_{\mathrm{f}} \times 10^{-3}$ \\
\hline With Allowance & $\mathrm{R}_{\mathrm{F}}$ & $\mathrm{R}_{\mathrm{TBH}}$ & $\mathrm{R}_{\mathrm{T}}$ & $1.71+0.4$ \\
ITTC & 62.7344 & 79.09 & 85.14 & $1.71+0.4$ \\
ATTC & 62.7344 & 79.09 & 85.14 & $1.71+0.4$ \\
Granville & 62.7344 & 79.09 & 85.14 & $1.52+0.4$ \\
Hughes & 57.0853 & 73.44 & 79.21 & 1.71 \\
Without Allowance & & & & 1.71 \\
ITTC & 50.84 & 67.20 & 72.66 & 1.71 \\
ATTC & 50.00 & 67.20 & 72.66 & 1.52 \\
Granville & 50.00 & 67.20 & 72.66 & 69.80 \\
Hughes & 45.19 & 61.55 & & \\
\hline
\end{tabular}

Table 3: Ocean-Going Tug Main Particular

\begin{tabular}{ll}
\hline Parameter & Value \\
Length Overall $\mathrm{L}_{\mathrm{OA}}$ & $60.96 \mathrm{~m}$ \\
\hline Length Between Perpendicular $\mathrm{L}_{\mathrm{pp}}$ & $33.86 \mathrm{~m}$ \\
Breadth $\mathrm{B}_{\mathrm{x}}$ & $16.002 \mathrm{~m}$ \\
Height H & $96.0198 \mathrm{~m}$ \\
Volume Displacement & $2749.57 \mathrm{~m}^{3}$ \\
Mass Displacement & 2775 tons $^{2}$ \\
Wetted Surface Area S & $1133.38 \mathrm{~m}^{2}$ \\
Block Coefficient $\mathrm{C}_{\mathrm{B}}$ & 0.465 \\
Prismatic Coefficient $\mathrm{C}_{\mathrm{P}}$ & 0.586 \\
$\mathrm{C}_{\mathrm{x}}$ & 0.794 \\
$\mathrm{~B}_{\mathrm{x}} / \mathrm{H}$ & 2.66 \\
$\mathrm{~V}_{\mathrm{s}}$ & $7.71 \mathrm{~m} / \mathrm{s}$ \\
$\mathrm{T}(\mathrm{sw})$ & $15^{0} \mathrm{C}$ \\
\hline
\end{tabular}

Table 4: Numerical Result for Ocean-Going Tug

\begin{tabular}{|c|c|c|c|c|}
\hline Methods & Resistanc & & & $\mathrm{C}_{\mathrm{f}} \times 10^{-3}$ \\
\hline With Allowance & $\mathrm{R}_{\mathrm{F}}$ & $\mathrm{R}_{\mathrm{TBH}}$ & $\mathrm{R}_{\mathrm{T}}$ & \\
\hline ITTC & 73.265 & 213.57 & 229.765 & $1.72+0.4$ \\
\hline ATTC & 73.265 & 213.57 & 229.765 & $1.72+0.4$ \\
\hline Granville & 73.265 & 213.57 & 229.765 & $1.72+0.4$ \\
\hline Hughes & 66.700 & 207.00 & 222.52 & $1.53+0.4$ \\
\hline \multicolumn{5}{|c|}{ Without Allowance } \\
\hline ITTC & 59.44 & 199.75 & 214.51 & 1.72 \\
\hline ATTC & 59.44 & 199.75 & 214.91 & 1.72 \\
\hline Granville & 59.44 & 199.75 & 214.91 & 1.72 \\
\hline Hughes & 52.88 & 193.18 & 208.00 & 1.53 \\
\hline
\end{tabular}

Table 5: Container Ship Main Particular

\begin{tabular}{|c|c|}
\hline Parameter $\mathrm{L}_{\mathrm{WL}}$ & Value $280 \mathrm{~m}$ \\
\hline Breadth $B_{x}$ & $33 \mathrm{~m}$ \\
\hline Height $\mathrm{H}$ & $11 \mathrm{~m}$ \\
\hline Volume Displacement & $8972 m^{3}$ \\
\hline Wetted Surface Area S & $111000 \mathrm{~m}^{2}$ \\
\hline Block Coefficient $C_{B}$ & 0.62 \\
\hline $\mathrm{V}_{\mathrm{s}}$ & $12.85 \mathrm{~m} / \mathrm{s}$ \\
\hline $\mathrm{T}(\mathrm{sw})$ & $15^{0} \mathrm{C}$ \\
\hline Scale Ratio & 20 \\
\hline
\end{tabular}


Table 6: Numerical Result for Container Ship

\begin{tabular}{|c|c|c|c|c|}
\hline Methods & Resistance & & & $\mathrm{C}_{\mathrm{f}} \times 10^{-3}$ \\
\hline With Allowance & $\mathrm{R}_{\mathrm{F}}$ & $\mathrm{R}_{\mathrm{TBH}}$ & $\mathrm{R}_{\mathrm{T}}$ & \\
\hline ITTC & 1647.13 & 2194.54 & 2368.70 & $1.3512+0.4$ \\
\hline ATTC & 1647.13 & 2217.00 & 2392.85 & $1.3512+0.4$ \\
\hline Granville & 1631.32 & 2259.25 & 2437.21 & $1.3344+0.4$ \\
\hline Hughes & 1495.51 & 2355.19 & 2537.95 & $1.1900+0.4$ \\
\hline \multicolumn{5}{|c|}{ Without Allowance } \\
\hline ITTC & 1271.00 & 1818.30 & 1973.90 & 1.3512 \\
\hline ATTC & 1271.00 & 1840.69 & 1997.69 & 1.3512 \\
\hline Granville & 1255.10 & 1883.70 & 2043.55 & 1.3344 \\
\hline Hughes & 1119.28 & 1982.72 & 2146.86 & 1.1900 \\
\hline
\end{tabular}

Table 7: Numerical Result of Speed Variation

\begin{tabular}{|c|c|c|c|c|c|c|c|c|c|}
\hline & & \multirow{2}{*}{\multicolumn{8}{|c|}{ OCEAN-GOING TUG }} \\
\hline \multirow{2}{*}{\multicolumn{2}{|c|}{ CARGO SHIP }} & & & & & & & & \\
\hline & & \multicolumn{3}{|c|}{$\mathrm{C}_{\mathrm{F}} \times 10^{-3}$} & \multicolumn{2}{|c|}{ 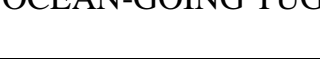 } & \multicolumn{3}{|c|}{$\mathrm{C}_{\mathrm{F}} \times 10^{-3}$} \\
\hline $\mathrm{V}_{\mathrm{s}}$ (knots) & $\mathrm{R}_{\mathrm{n}} \times 10^{8}$ & ITTC & HUGHES & GRANVILLE & $\mathrm{V}_{\mathrm{s}}$ (knots) & $\mathrm{R}_{\mathrm{n}} \times 10^{8}$ & ITTC & HUGHES & GRANVILLE \\
\hline 6 & 3.16 & 1.77 & 1.58 & 1.77 & 6 & 1.59 & 1.95 & 1.73 & 1.95 \\
\hline 8 & 4.22 & 1.71 & 1.52 & 1.71 & 8 & 2.11 & 1.87 & 1.67 & 1.87 \\
\hline 10 & 5.27 & 1.66 & 1.47 & 1.66 & 10 & 2.64 & 1.82 & 1.61 & 1.82 \\
\hline 12 & 6.33 & 1.62 & 1.44 & 1.72 & 12 & 3.16 & 1.77 & 1.56 & 1.77 \\
\hline 14 & 7.38 & 1.59 & 1.41 & 1.59 & 14 & 3.65 & 1.74 & 1.55 & 1.74 \\
\hline 16 & 8.43 & 1.56 & 1.39 & 1.56 & 16 & 4.21 & 1.71 & 1.52 & 1.71 \\
\hline
\end{tabular}

Table 8: Numerical Result of Effective Power Developed at Experimental Speeds

\begin{tabular}{lc}
\hline $\mathrm{V}_{\mathrm{S}}$ & $\mathrm{P}_{\mathrm{E}}(\mathrm{kW})$ \\
\hline 6 & 666.775 \\
8 & 1580.814 \\
10 & 3086.921 \\
12 & 5334.200 \\
14 & 8470.512 \\
16 & 12014.65 \\
\hline
\end{tabular}

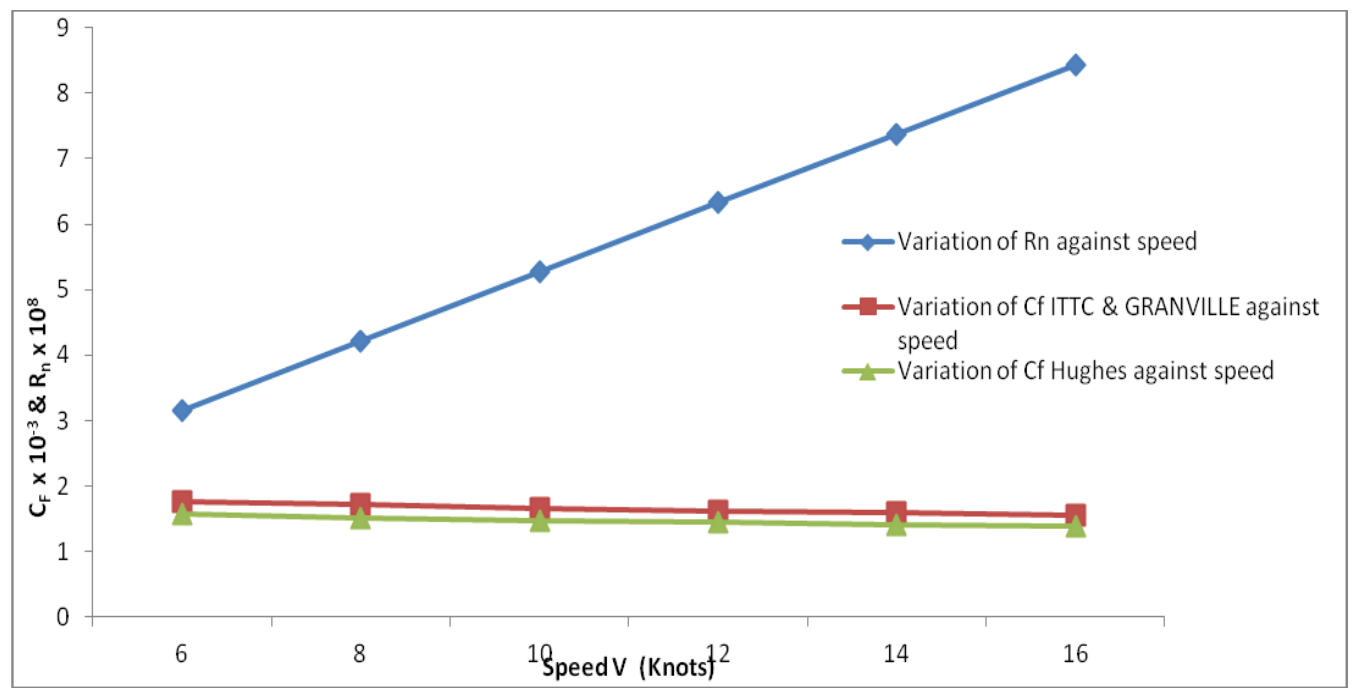

Fig. 1: Total Frictional Resistance Coefficient and Reynolds Number against Speed for Cargo Ship. 


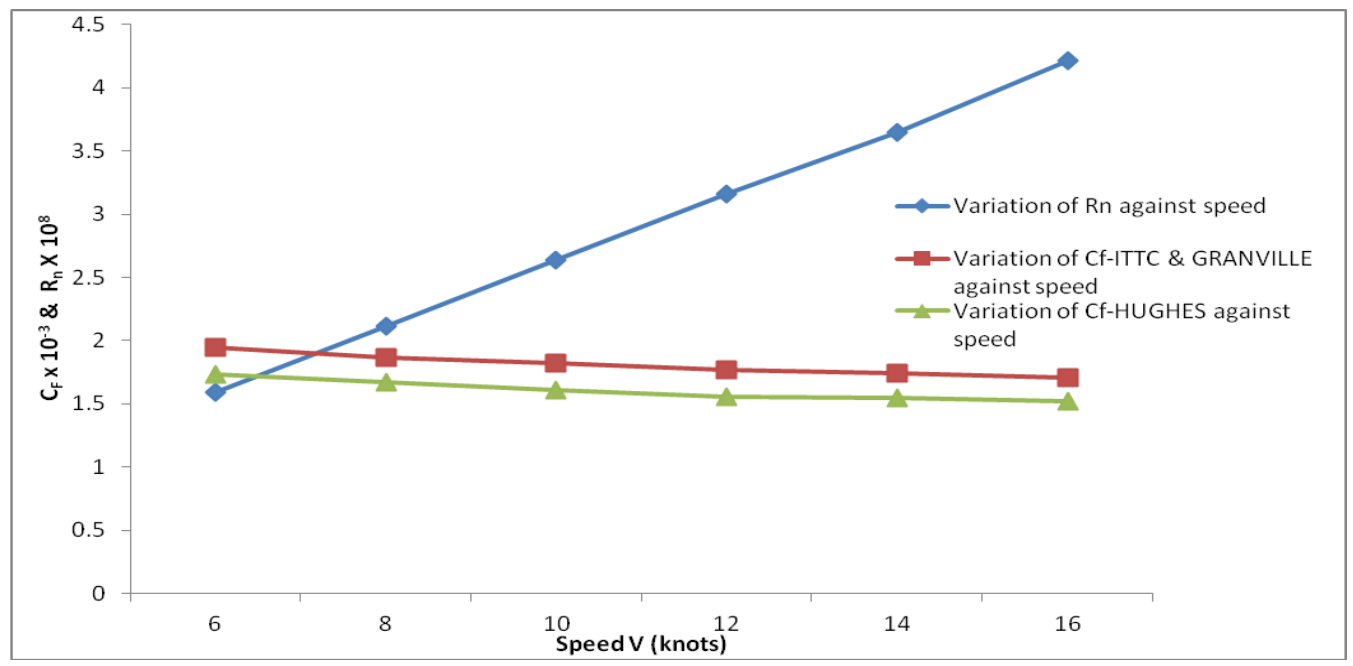

Fig 2: Total Frictional Resistance Coefficient and Reynolds Number against Speed for Ocean-Going Tug.

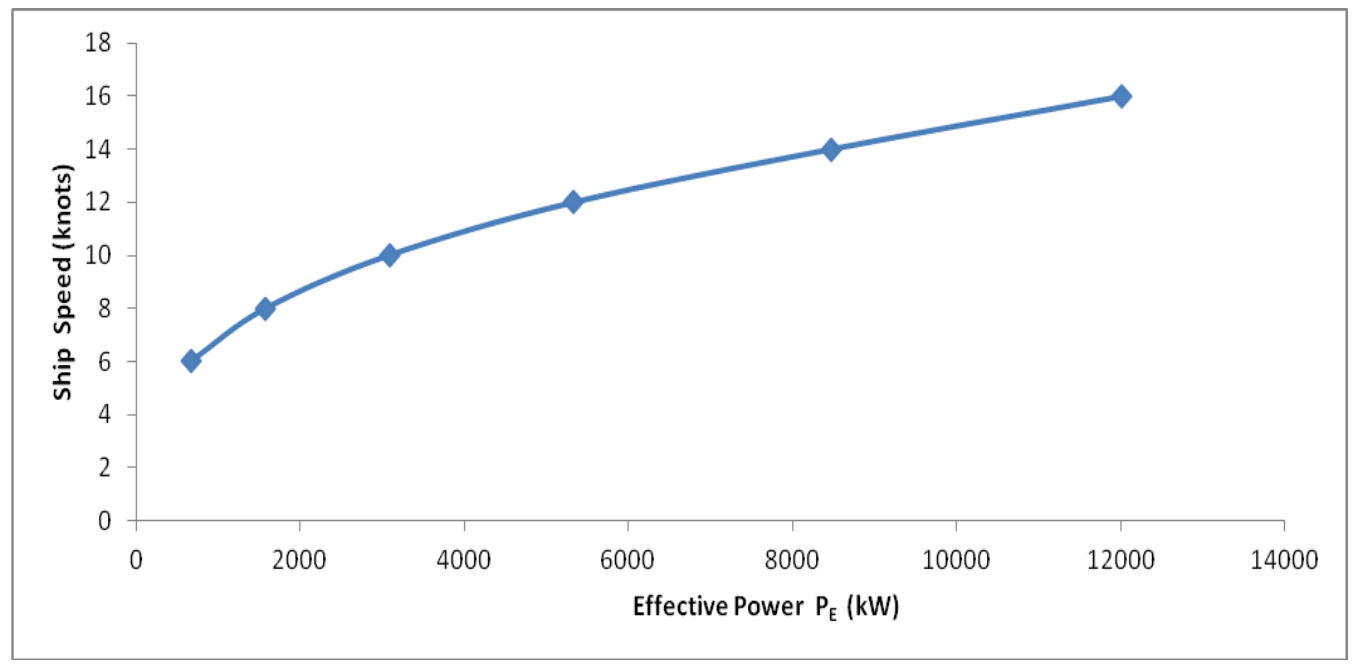

Fig. 3: The Ship Speed of the Containership against the Effective Power Developed.

It has been observed from the first, second and third simulation for Cargo ship, Ocean-going Tug and Container Ship that Hughes gives a decrease in coefficient of frictional resistance as such the following was obtained. The first simulation on Cargo Ship obtained from ITTC; ATTC and Granville lines gave an increase of $2.31 \%\left(\mathrm{R}_{\mathrm{F}}\right), 1.87 \%\left(\mathrm{R}_{\mathrm{TBH}}\right)$ and $1.77 \%\left(\mathrm{R}_{\mathrm{T}}\right)$ and when used without the +0.0004 correlation allowance, the increase obtained are $2.85 \%\left(\mathrm{R}_{\mathrm{F}}\right)$, $2.15 \%\left(\mathrm{R}_{\mathrm{TBH}}\right)$ and $0.99 \%\left(\mathrm{R}_{\mathrm{T}}\right)$, over Hughes Line Method. When the allowance is used in each case the results in all three methods ITTC, ATTC and Granville give the same results for $R_{F}, R_{T B H}$, and $R_{T}$, this is due to the same coefficient of frictional resistance.

In the second simulation for Ocean-going Tug, ITTC, ATTC and Granville line gave an increase of $2.28 \%\left(\mathrm{R}_{\mathrm{F}}\right)$, $0.77 \%\left(\mathrm{R}_{\mathrm{TBH}}\right)$ and $0.79 \%\left(\mathrm{R}_{\mathrm{T}}\right)$. When used without the correlation allowance, it gave an increase in $\mathrm{R}_{\mathrm{F}}$ to $2.85 \%, \mathrm{R}_{\mathrm{TBH}}$ to $2.15 \%$ and $\mathrm{R}_{\mathrm{T}}$ to $0.99 \%$ over Hughes line method which is almost the same with the first simulation.

In the third simulation of Container Ship, the Reynolds number value leads to divergence in the coefficient of frictional resistance. This is due to inconsistency in values approximation on the small models. This does are not provides sufficient steps to give good correlation between the results of small models and large ships. Nevertheless, results of ATTC and ITTC line methods are the same which showed a decrease from Granville line method in $\mathrm{R}_{\mathrm{T}}$ as $0.14 \%, \mathrm{R}_{\mathrm{TBH}}$ as $0.72 \%$ and increase in $\mathrm{R}_{\mathrm{F}}$ as $0.25 \%$. The Hughes gave a general increases over the three methods (ATTC, ITTC and Granville) in $\mathrm{R}_{\mathrm{TBH}}, \mathrm{R}_{\mathrm{T}}$ and decrease in $\mathrm{R}_{\mathrm{F}}$. From the results, it was observed that when there is no addition of +0.0004 correlation allowance, one needs to be carefully with approximation in order not to have diverge value. Table 8 and Fig. 3 indicated that for every 1 knots increase in the speed, the effective power developed by the Container ship increases by $9.45 \%$. '

It also revealed from Fig. 1 and Fig. 2 that as the speed increases the coefficient of friction decrease while the Reynolds number increases. This simply implies that the faster the ship movement will be and the lesser the bare hull resistance. However, from Hughes's friction line analysis, a lower coefficient of friction was obtained compared with that of Granville and ITTC. 


\section{Conclusion}

It was indicated from the model that there exist an improved correlation with the data of measurement to the approximated results. However, the results of the models were validated with the similarity check, and it exhibits a general applicable standard.

The four different series used in the analysis such as ITTC, ATTC, GRANVILLE AND HUGHES showed a progressives increase in the hull form resistance as the degree of turbulence increase as well as the increase in speed. This was applied at the same beam to draft and length to beam ratio. The results show the comparative trend of the bare hull resistance as well as the residuary resistance for the three vessels under the various considerations. The residuary resistance was also factored in the expression of the total resistance in the vessel in operation. Figures 1 and 2 modeled the trend of resistance coefficient and Reynolds number increment with speed at an even interval for both the Cargo ship and the Ocean-going tug. The values from the numerical models are quite good with a good degree of precision to predict the trend of the resistance on the three ship types analysed.

Therefore, modeling the hull form resistance trend will enable a better prediction of the ship experience in operation. This gives a phenomenal explanation of the hull form interaction with resistance for the three ocean-going vessels. Conclusively, the results gave fair approximated and predicted values of the total hull form resistance for the three ocean going vessels based on the comparative assessment in term of ITTC, ATTC, Hughes and Granville models.

\section{References}

[1] Breslin, S. \& Anderson P. Hydrodynamics of ship Propellers, Cambridge: Cambridge University Press, (1994).

[2] Journee, J.M. J. Motion, Resistance and Propulsion of Ship in Regular Head waves, Delft University of Technology, Report 0428, (1976).

[3] Chang, M. S. Wave Resistance Predictions using a Singularity Method, Workshop on Wave Resistance Computation, David Taylor Naval Ship Research and Development Center, Bethesda, MD, (1979).

[4] Donnelly J. B. Resistive Forces Analysis Volume 3 Foster Wheeler Powder Products Ltd.

[5] Aribas, F. P Some methods to obtain the added resistance of a ship advancing in waves. Ocean Engineering (Elsevier) 34: 946-955, (2006) http://dx.doi.org/10.1016/j.oceaneng.2006.06.002.

[6] Harvald, S. A. Resistance a\&propulsion of Ship, Wiley (1983).

[7] Havelock, T.H, Drifting force on a ship among waves. 33. (1942). Philosophical Magazine http://dx.doi.org/10.1080/14786444208521213.

[8] Stron-Tejsen Added Resistance in wave. Transactions of the SNAME 81, 109-143, (1973)

[9] ITTC Report of the Resistance and Flow Committee, 21st International Towing Tank Conference Trondheim, Norway, 439-514, (1996).

[10] Ogiwara S. Stern flow measurements for the Tanker 'Ryuko-Maru' in model scale, Intermediate scale and full scale ships, proceedings of CFD Workshop Tokyo 1, 341-349, (1994).

[11] Taylor D. A. Introduction to marine Bare Resistance Broken Analysis 2nd Edition, (1986).

[12] Schneekluh, H. \& Bertram V. Ship Design for Efficiency and Economy, 2nd Edition, (1998) Butterworth-Heinemann

[13] Antonia J. \& Henry W. S. Modern Marine Engineers, Cornell Marine Press Inc. (1978).

[14] Nitonye, S. \& Adumene, S Predictive analysis of Bare - Hull Resistance of a 25000Dwt Tanker vessel, International Journal of Engineering and Technology 5(4): 194-198, (2015)

[15] Nitonye S. Stress and Resistance analysis for the design of a work barge. International Journal of Scientific and Engineering Research, 6(5) 878-894 (2015). 